\title{
Detection and identification of potentially toxic cyanobacteria in Polish water bodies
}

\author{
Joanna Głowacka, Magdalena Szefel-Markowska, Małgorzata Waleron, Ewa Łojkowska \\ and Krzysztof Waleron
}

Department of Biotechnology, Intercollegiate Faculty of Biotechnology, University of Gdańsk and Medical University of Gdańsk, Gdańsk, Poland

The main goal of this study was to determine the distribution of potentially toxic cyanobacteria in 39 selected Polish water bodies. From the water bodies with blooms and also from those in which blooms were not visible 87 samples were investigated. For the first time samples from ponds localized in villages with high agricultural activities were included. Lakes for which microcystin concentrations had been determined before were included as a reference for the research. The detection of cyanobacteria was conducted by microscopic observation as well as by PCR amplification of the rpoC1 gene fragment. Cyanobacteria were present in 75 out of 87 samples. The presence of potentially toxic cyanobacteria was detected by amplification of the $m c y B$ and $m c y E$ genes, which are involved in the biosynthesis of microcystins. Both genes were detected in 7 out of 9 blooms investigated. In the case of samples collected from water bodies in which blooms were not observed, the mcy $B$ and mcyE genes were detected in 20 out of 36 . In order to identify the cyanobacteria occurring in selected reservoirs, 16S plus ITS clone libraries were constructed. The method allowed distinguishing 18 different genotypes. After sequence analysis, cyanobacteria belonging to genera Microcystis, Planktothrix, Anabaena, Pseudanabaena, Synechocystis, Synechococcus and Woronichinia were identified. Results confirmed the usefulness of the rpoC1 and mcy genes for monitoring water bodies and detection of potentially toxic cyanobacteria. Application of molecular markers allowed detecting potentially toxic cyanobacteria before the bloom was visible. This is the first comprehensive study concerning cyanobacteria present in different types of Polish water bodies performed using molecular markers.

Keywords: Cyanobacteria, toxins, microcystins, rpoC1, mcyE, mcyB, 16S rRNA

Received: 22 November, 2010; revised: 19 January, 2011; accepted: 01 July, 2011; available on-line: 11 July, 2011

\section{INTRODUCTION}

Cyanobacteria (blue-green algae) are one of the largest group of Gram-negative, chlorophyll-a containing, photosynthetic prokaryotes. They are morphologically diverse and widespread in both marine and terrestrial habitats. Cyanobacteria have been traditionally distinguished on the basis of phenotypic (morphological and physiological) properties. Because of limitations of this approach, it is commonly accepted that the modern cyanobacterial taxonomy should be supplemented by mo- lecular methods. Molecular techniques have facilitated culture-independent studies and identification of microorganisms collected from environment and difficult to culture. In addition, molecular methods do not require axenic cultures. The importance of the polyphasic approach, combining morphological observations with molecular data in improving the taxonomy of cyanobacteria is unquestionable.

The $r_{0} \mathrm{Cl}$ gene, coding for the $\gamma$ subunit of RNA polymerases, is recommended as a molecular marker for the detection and identification of cyanobacteria (Jameson et al., 2008; Yoshida et al., 2008; Valerio et al., 2009). The DNA-dependent RNA polymerase of cyanobacteria contains a unique core subunit $\gamma$, which is not present in the RNA polymerases of other eubacteria (Bergsland \& Haselkorn, 1991). This subunit is a common and unique feature of the core RNA polymerase of cyanobacteria and plastids, so the $r p o C 1$ gene coding for this subunit is a good molecular marker for detection and identification of these microorganisms.

Certain species of cyanobacteria are able to produce cyanotoxins, which can be hazardous for humans and animals. Cyanotoxins are arranged in four classes according to their specific activities: the neurotoxins (anatoxin, anatoxin-a(s), saxitoxin), hepatotoxins (microcystins, nudularins, cylindrospermopsins), dermatotoxins and cytotoxins (lyngbyatoxin-a, aplysiatoxins), endotoxins (LPS, lipopolysaccharides) (Codd et al., 2005).

In Polish water reservoirs, the most commonly detected cyanotoxins are microcystins, which can be produced by strains of the distantly related cyanobacterial genera: Microcystis, Anabaena, Planktothrix, and more rarely Anabaenopsis, Hapalosiphon and Nostoc (Jurczak et al., 2004; Izydorczyk et al., 2005; Mankiewicz et al., 2005; Palus et al., 2007; Mazur-Marzec, 2008, Mankiewicz-Boczek et al., 2009; Gagała et al., 2010, WIOŚ Gdańsk, 2010).

Microcystins can be accumulated in organs of plants and animals (fish, water birds, turtles) and create a potential risk to human health in case of their consumption (Chen et al., 2009). Microcystins are potent inhibitors of eukaryotic protein phosphatases types 1 and $2 \mathrm{~A}$ and act as tumor promoters (Codd et al., 2005). It has been reported that $50-75 \%$ of cyanobacterial blooms release

e-mail: waleron@biotech.ug.gda.pl

Abbreviations: Adda, 3-amino-9-methoxy-2,6,8-trimethyl-10-phenyl-4,6-decadienoic acid; BLAST, Basic local alignment search tool; ELISA, enzyme-linked immunosorbent assay; HPLC, high performance liquid chromatography; MALDI-TOF, matrix-assisted laser desorption/ionization/time of fligh; MS, mass spectrometry; PPIA, protein phosphatase inhibition assay; WIOŚ Regional Inspectorate for Environment Protection. 
the toxins in the water, and even up to $95 \%$ of blooms formed by Microcystis are toxic (Sivonen, 1996).

Presently the main efforts are concentrated on the monitoring and prediction of the appearance of cyanobacterial toxic water blooms. Because cyanobacteria with the potential to produce toxins have no characteristic morphological traits, their distinction from those that are nontoxic is not possible by microscopic observations. Routinely the detection of microcystins is carried out by enzyme-linked immunosorbent assay (ELISA), phosphatase inhibition assays (PPIA) as well as high performance liquid chromatography (HPLC) or mass spectrometry (MS), matrix-assisted laser desorption/ionization/ time of fligh (MALDI-TOF). However, such analyses do not indicate the potential of the appearance of toxins and do not allow the identification of the cyanobacteria producing toxins.

Polymerase chain reaction (PCR)-based detection of genes involved in the synthesis of microcystins (movB and $m y E$ ) is rapid and cost-effective. Assays such as real-time PCR, multiplex-PCR, semi-nested-PCR and microarray DNA chip technology have increased the sensitivity and specificity of the PCR. Recently, molecular methods are more often used for the detection of microcystin-encoding genes (Ouellette et al., 2005; Sivonen, 2008; Ha et al., 2009).

Molecular techniques allow identification of cyanobacteria, including the microcystin-producing cyanobacteria and also provide information about the presence of genes coding for the toxins in water bodies before populations of cyanobacteria develop fully (Codd et al., 2005). This is essential for health protection of water users and for the conservation of water resources and habitats.

Microcystins are cyclic heptapeptides, which are synthesized nonribosomally by multifunctional enzymes that include polypeptide synthetase and polyketide synthase modules. This group of toxins is encoded by microcystin synthetase (mcy) gene cluster, which contains $55 \mathrm{~kb}$ of DNA (Tillett et al., 2000; Rouhiainen et al., 2004). More than 70 microcystin structural variants are known (Codd et al., 2005).

The aims of this study was to check usefulness of the application of molecular methods for detection of cyanobacteria by PCR amplification of the $r_{p o} C 1$ gene fragment and monitoring of the presence of toxic cyanobacteria by PCR amplification of genes coding for microcystin synthetase in 36 selected Polish water bodies.

\section{MATERIALS AND METHODS}

Samples collected from water bodies. Sampling were conducted from nine water bodies Bnińskie Lake, Bytyńskie Lake, Klasztorne Duże Lake, Trzesiecko Lake, Tuchom Lake, pond in Drzewce, pond in Gumnisko, pond in Mniewo and Sulejów Reservoir during bloom of cyanobacteria and also, when mass occurrence of cyanobacteria was not observed (Table 1). Samples gathered when bloom was not visible were from 20 lakes: Bielsko, Chodzieskie, Ciemino, Dobre, Dolsko, Jeleń, Jelonek, Karlikowskie, Kamienickie, Kielno, Klasztorne Duże, Krą, Mausz, Ostrzyckie, Raduńskie Dolne, Straszyn, Trzesiecko, Tuchom, Wysoka and Żur; five reservoirs: Dojlidy, Sulejów, Zemborzyce, Nadarzyce and Lagoon of Wistula; three ponds in Gumnisko, Kowalewo, and Mniewo; six rivers: Gwda, Łeba, Noteć, Słupia, Tralalka and Radunia;
Gulf of Gdańsk (Orłowo, Puck, Gdynia and Osłonino); Baltic Sea (Orzechowo and Rowy) (Table 1).

Cultures of cyanobacteria. Strains Microcystis sp. PCC 7806, Microcystis sp. PCC 7941, Microcystis sp. PCC 7005, Planktothrix sp. PCC 7821, Planktothrix sp. PCC 7805, Cyanobium sp. PCC 6307, Gloeothece sp. PCC 6501 and Dermocarpella sp. PCC 7326 were obtained from the Pasteur Culture Collection, Paris, France. These strains of cyanobacteria were grown in BG11, BG112N10 and Z8 medium (Rippka, 1988) at $20^{\circ} \mathrm{C}$ and under photoperiod conditions (18 h day: $6 \mathrm{~h}$ night).

Sampling and DNA extraction. To examine the community of cyanobacterial populations in blooming water, samples were collected early morning from the surface and a depth of $0.5 \mathrm{~m}$ in the offshore zone. Nine water samples were collected during blooms of cyanobacteria (Table 1). The dominant cyanobacteria were identified directly in samples using a light microscope (Nicon, Eclipse E600). For DNA preparation, cells were harvested by centrifugation and suspended in TE buffer (50 mM Tris/HCl, 40 mM EDTA, pH 8.0). Cyanobacterial DNA was extracted using SDS/proteinase K.

Seventy-eight water samples were collected from 36 water reservoirs in which cyanobacterial blooms were not observed. For microscopic identification 1-2 ml samples of water were centrifuged, pellet was resuspended in $100 \mu$ l volume of water and subsamples placed into a nanoplankton counting chamber filamentous, colonial and single-celled algal forms were identified to the generic level according to taxonomic keys based on cell or colony morphology (Komarek \& Anagnostidis, 2000; 2005).

For DNA analysis $500 \mathrm{ml}$ of each sample was filtered by using two kinds of filters $(\Phi 8 \mu \mathrm{m}$ and 0.2 $\mu \mathrm{m})$. This procedure allowed separation of colonyforming and filamentous cyanobacteria fraction from single-cell forms. Filters with collected cyanobacterial cells were frozen at $-20^{\circ} \mathrm{C}$. Cyanobacterial DNA was extracted from cells using the protocol described by Waleron et al. (2007).

DNA amplification. The detection of cyanobacteria in water samples was conducted by amplification of the rpoC1 gene fragment. PCR products were amplified using primers rpoC3 (5'-CCCGCNAARGAYTGGGAATG-3') and rpoC4 (5'-GCT'TCYTGCARCATCCGYT'TYTC-3') to produce a 729-base pair (bp) product. The amplification reaction was performed with the Biometra Thermocycler, as follows: initial denaturation step $\left(94^{\circ} \mathrm{C}\right.$, $5 \mathrm{~min}$ ), followed by 36 cycles of denaturation $\left(94^{\circ} \mathrm{C}\right.$, $50 \mathrm{~s})$, annealing $\left(53^{\circ} \mathrm{C}, 1 \mathrm{~min}\right)$ and extension $\left(72^{\circ} \mathrm{C}, 2\right.$ $\mathrm{min})$, with a final extension step $\left(72^{\circ} \mathrm{C}, 7 \mathrm{~min}\right)$. Each reaction was carried out in a volume of $50 \mu \mathrm{l}$ containing: $5 \mu \mathrm{l}$ of $10 \mathrm{x}$ reaction buffer (Fermentas), $2 \mathrm{mM}$ $\mathrm{Mg}^{2+}, 0.25 \mathrm{mM}$ of each of the four deoxynucleoside triphosphates (dNTPs), $5 \mu \mathrm{l}$ of BSA, $10 \mathrm{mg} / \mathrm{ml}, 20$ pmol of each primer, 50-100 ng of DNA and $1 \mathrm{U}$ of recombinant Taq DNA polymerase (MBI Fermentas). The obtained products were electrophoretically separated in $1.2 \%$ agarose gel at $7 \mathrm{~V} / \mathrm{cm}$ for $2 \mathrm{~h}$ in TAE buffer and subsequently stained with ethidium bromide $(0.5 \mu \mathrm{g} / \mathrm{ml})$ and visualized under UV. In order to detect potentially toxic cyanobacteria, mcyB and $m y E$ gene fragments were amplified. For each sample, two separate PCRs were conducted. The 320 bp fragment of the microcystin peptide synthetase B gene $(m c y B)$ was obtained with Mcy F1 and Mcy R1 primers (Nonneman \& Zimba, 2002). Fragment of 
myE gene (809-812 bp) was amplified using primers mcyE-F2 and mcyE-R4 (Vaitomaa et al., 2003). Mcy F1 and Mcy R1 are specific primers to detect potentially microcystin-producing Microcystis, whereas mcyEF2 and mcyE-R4 are general primers to detect different potentially toxic strains of cyanobacteria. Both PCR reactions were conducted according to the protocols previously described by Nonneman and Zimba (2002) and Vaitomaa et al. (2003). The obtained products were electrophoretically separated under the same conditions as described for the $r p o C 1$ gene.

Amplification of 16S rRNA + ITS + 5' end of 23S rRNA gene was carried out as the first step to generate clone libraries. Primers CYA359F, 23S30R and PCR parameters were as described by Nübel et al. (1997) and Taton et al. (2003). Products were electrophoretically separated as above.

Clone library generation and analysis. For each library, three separate PCR reactions were carried out. The aim of this step was to minimize the bias caused by the PCR reaction. Obtained products were mixed and purified with a Clean-Up system (A\&A Biotechnology), according to Vendor's instructions. Clone libraries were created using pGEM-T ${ }^{\circledR}$ Easy Vector (Promega) and Strata Clone ${ }^{\mathrm{TM}}$ PCR Cloning Vector pSC-A cloning kit. White and light-blue transformants were purified by streaking and screened for the presence of insert DNA by performing colony PCR with primer pair CYA359F and 23 S30R for amplification of $16 \mathrm{~S}$ rRNA + ITS + 5' end of $23 \mathrm{~S}$ rRNA gene. The amplification conditions were as described above.

Restriction fragment length polymorphism analysis (RFLP) of cloned PCR product of rrn fragment (16S rRNA + ITS + 5'end of $23 \mathrm{~S}$ rRNA).

For RFLP analysis of the rrm amplicon, restriction endonuclease MspI (Fermentas) was applied. Digestion was carried out $4 \mathrm{~h}$ at $37^{\circ} \mathrm{C}$. Each reaction was carried out in a volume of $30 \mu \mathrm{l}$ containing: $0.25 \mu \mathrm{l}$ MspI (10 $\mathrm{U} / \mu \mathrm{l}$ ), $3 \mu \mathrm{l}$ of $10 \times$ buffer $\mathrm{B}$ (Promega) and sterile water (Fluka). Fragments were separated in 2\% agarose gel electrophoresis and visualized as described above. The genotypes with similar RFLP patterns were grouped and one clone of each genotype (each RFLP pattern) was sequenced.

Plasmid isolation and sequencing. Plasmids containing $r m$ fragments differentiated by RFLP were isolated with Plasmid Mini (A\&A Biotechnology) miniprep system. Before sequencing, the concentration of plasmid DNA was measured with NanoDrop (NanoDrop Technologies, Inc.). The DNA was further diluted with sterile water to give a concentration of $70-80 \mathrm{ng} / \mu \mathrm{l}$. Sequencing of samples that gave different RFLP patterns was conducted using the CYA359F primer (Nübel et al., 1997). Sequencing was carried out in the Pomeranian Science and Technology Park in Gdynia, Poland.

Analysis of sequence data. Obtained sequences were manually edited with BioEdit software (http:// www.mbio.ncsu. edu/BioEdit/bioedit.html), which was incorporated for sequence alignment based on automated ClustalW alignment. Basic local alignment search tool (BLAST) algorithm was conducted through the NCBI Web site (http://www.ncbi.nih. gov). For each cloned sequence, the BLAST result with the highest sequence similarity was chosen ( $\mathrm{Ta}$ ble 2). The attribution of detected cyanobacterial sequences to particular genus was conducted according to definition of bacterial "species" and "genus" proposed by Stackebrandt and Goebel (1994). Therefore, the similarity value for the $16 \mathrm{~S}$ rRNA gene sequence higher than $97.5 \%$ indicated that two cyanobacterial strains belong to the same genus.

\section{RESULTS}

\section{Microscopic observation and identification of cyanobacteria}

On the basis of morphological observation of bloom samples, two genera of cyanobacteria were identified. In lakes Bnińskie, Bytyńskie, Klasztorne Duże and in the pond of Gumnisko thin, filamentous, nonheterocystous cyanobacteria belonging to genus Planktothrix were observed. In the remaining water bodies, we identified colonies of Microcystis (Table 1).

The microscopic analysis of samples collected from water bodies in which a mass occurrence of cyanobacteria was not observed, indicated the presence of cyanobacteria in 54 samples (Table 1). Potentially toxic cyanobacteria were identified in 19 water bodies. Microcystis, Planktothrix and Anabaena were identified, respectively, in 12,7 and 13 water bodies (Table 1).

\section{Detection of cyanobacteria using molecular markers}

The presence of cyanobacteria in water bodies was analyzed using PCR amplification of the $r p o C 1$ gene fragment. The occurrence of cyanobacteria was revealed in 75 samples $(86.2 \%)$ collected from 39 different water bodies including all nine blooming water bodies (100\%) and 34 non-blooming water bodies (Table 1).

To determine the presence of potentially toxic (toxigenic) cyanobacteria in water bodies with blooms the amplification of $m c y B$ and $m y E$ genes required for synthesis of microcystins was applied (Table 1). These genes were also amplified from cultures of Microcystis sp. PCC 7806, Microcystis sp. PCC 7941, Planktothrix sp. PCC 7821, PCC 7805, whose ability to produce microcystins is well known (Table 1). As negative controls, DNA extracted from nontoxic strains: Microcystis sp. PCC 7005, Cyanobium sp. PCC 6307, Gloeothece sp. PCC 6501 and Dermocarpella sp. PCC 7326 was used as a template (Table 1).

The presence of $m c y B$ was confirmed in 7 out of 9 water bodies and of mcyE in all water bodies in which cyanobacterial blooms were observed (Table 1). Among the 36 non-blooming water bodies the presence of rpoC1 PCR product was confirmed in 34 (84.6\%). Cyanobacteria that have the potential for the production of toxins were identified by detection of $m y E$ and $m y B$ genes in 41 samples collected from 20 water bodies ( $\mathrm{Ta}$ ble 1). It is worth underlining that the $m c y B$ or/and $m c y E$ PCR products were not detected in samples in which the presence of cyanobacteria was not confirmed by amplification of the rpoC1 gene fragment and microscopic observation (Table 1).

The analysis of one sample from Mausz Lake (July 2004) indicated the presence of potentially toxic cyanobacteria other than Microcystis, because only the moy gene was amplified (Table 1). Both toxicity markers, $m c y E$ and $m c y B$, were detected in only one out of five running waters, the Notec.

Monitoring of water bodies showed that in Klasztorne Duże, Ostrzyckie, Kielno and Lagoon of Wistula, the presence of toxic cyanobacteria was observed in samples collected between July and October, in Trzesiecko lake between June and August, in Tuchom 
Table 1. Detection and identification of cyanobacteria and potentially toxic cyanobacteria

\begin{tabular}{|c|c|c|c|c|c|c|c|c|}
\hline \multirow{2}{*}{ No. } & \multirow{2}{*}{$\begin{array}{l}\text { Name and nature of } \\
\text { water bodies }\end{array}$} & \multirow{2}{*}{$\begin{array}{l}\text { Date of } \\
\text { sampling }\end{array}$} & \multicolumn{5}{|l|}{$\begin{array}{l}\text { Presence of } \\
\text { cyanobacteria }\end{array}$} & \multirow{2}{*}{$\begin{array}{l}\text { Microcystin's concentration } \\
\text { Sampling Date } \\
\text { (References) }\end{array}$} \\
\hline & & & $\begin{array}{l}\text { Microscopic } \\
\text { observation }\end{array}$ & $\begin{array}{l}\text { PCR } \\
\text { rpoC1 }\end{array}$ & $\begin{array}{l}\text { PCR } \\
m c y E\end{array}$ & $\begin{array}{l}\text { PCR } \\
m c y B\end{array}$ & $\begin{array}{l}\text { Identification of } \\
\text { potentially toxic } \\
\text { cyanobacteria }\end{array}$ & \\
\hline \multicolumn{9}{|c|}{ Reference strains } \\
\hline & & & $\begin{array}{l}\text { Microcystis sp. } \\
\text { PCC } 7806\end{array}$ & + & + & + & $\begin{array}{l}m c y B, m c y E-\text { po- } \\
\text { sitive }\end{array}$ & \\
\hline & & & $\begin{array}{l}\text { Microcystis sp. } \\
\text { PCC } 7941\end{array}$ & + & + & + & $\begin{array}{l}m c y B, m c y E-\text { po- } \\
\text { sitive }\end{array}$ & \\
\hline & & & $\begin{array}{l}\text { Planktothrix sp. } \\
\text { PCC } 7821\end{array}$ & + & + & - & $m c y E$ - positive & \\
\hline & & & $\begin{array}{l}\text { Planktothrix sp. } \\
\text { PCC } 7805\end{array}$ & + & + & - & $m c y E$ - positive & \\
\hline & & & $\begin{array}{l}\text { Microcystis sp. } \\
\text { PCC } 7005\end{array}$ & + & - & - & mcy - negative & \\
\hline & & & $\begin{array}{l}\text { Cyanobium sp. } \\
\text { PCC } 6307\end{array}$ & + & - & - & mcy - negative & \\
\hline & & & $\begin{array}{l}\text { Gloeothece sp. } \\
\text { PCC } 6501\end{array}$ & + & - & - & $m c y$ - negative & \\
\hline & & & $\begin{array}{l}\text { Dermocarpella } \\
\text { sp. PCC } 7326\end{array}$ & + & - & - & mcy - negative & \\
\hline \multicolumn{9}{|c|}{ Samples collected during bloom: } \\
\hline 1 & $\begin{array}{l}\text { Bnińskie Lake } \\
\text { agricultural and fore- } \\
\text { stry land }\end{array}$ & 20.09.2004 & Planktothrix & + & + & - & Planktothrix & $\begin{array}{l}10.47 \mu \mathrm{g} / \mathrm{L} \\
20.09 .2004 \\
\text { (Mankiewicz-Boczek et al., } \\
\text { 2006) }\end{array}$ \\
\hline 2 & $\begin{array}{l}\text { Bytyńskie Lake } \\
\text { agricultural and fore- } \\
\text { stry land }\end{array}$ & 20.09 .2004 & Planktothrix & + & + & - & Planktothrix & $\begin{array}{l}\text { 23.8, } 34.6 \mu \mathrm{g} / \mathrm{L} \\
06.2007 / 09.2007 \\
\text { (Mankiewicz-Boczek et al., } \\
\text { 2009) }\end{array}$ \\
\hline 3 & $\begin{array}{l}\text { Klasztorne Duże Lake } \\
\text { urban land }\end{array}$ & 11.08 .2004 & $\begin{array}{l}\text { Planktothrix } \\
\text { Microcystis }\end{array}$ & + & + & + & $\begin{array}{l}\text { Planktothrix } \\
\text { Microcystis }\end{array}$ & \\
\hline 4 & $\begin{array}{l}\text { Trzesiecko Lake } \\
\text { agricultural and urban } \\
\text { land }\end{array}$ & 20.08 .2004 & + & + & + & + & Microcystis & \\
\hline 5 & $\begin{array}{l}\text { Tuchom Lake } \\
\text { agricultural land }\end{array}$ & 30.08 .2003 & $\begin{array}{l}\text { Microcystis } \\
\text { Anabaena }\end{array}$ & + & + & + & Microcystis & $\begin{array}{l}>5 \mu \mathrm{g} / \mathrm{L} \\
23.06 .2003 \\
\text { (Mazur-Marzec, 2006) }\end{array}$ \\
\hline 6 & $\begin{array}{l}\text { Pond in Drzewce } \\
\text { agricultural land }\end{array}$ & 15.09 .2004 & $\begin{array}{l}\text { Microcystis } \\
\text { Anabaena }\end{array}$ & + & + & + & Microcystis & \\
\hline 7 & Pond in Gumnisko & 02.09 .2004 & Planktothrix & + & + & + & Planktothrix & \\
\hline 8 & $\begin{array}{l}\text { Pond in Mniewo } \\
\text { agricultural land }\end{array}$ & 10.08.2003 & $\begin{array}{l}\text { Microcystis } \\
\text { Anabaena }\end{array}$ & + & + & + & Microcystis & \\
\hline 9 & $\begin{array}{l}\text { Sulejów Reservoir } \\
\text { agricultural and fore- } \\
\text { stry land }\end{array}$ & 20.09.2004 & Microcystis & + & + & + & Microcystis & $\begin{array}{l}4.67 \mu \mathrm{g} / \mathrm{L} \\
22.09 .2004 \\
\text { (Mankiewicz-Boczek et al., } \\
\text { 2006) }\end{array}$ \\
\hline \multicolumn{9}{|c|}{ Samples collected from reservoirs in which bloom was not visible: } \\
\hline 1 & $\begin{array}{l}\text { Bielsko Lake } \\
\text { agricultural and fore- } \\
\text { stry land }\end{array}$ & 20.04 .2004 & $\begin{array}{l}\text { Merismopedia } \\
\text { Synechococcus }\end{array}$ & + & - & - & n.i. & \\
\hline \multirow[t]{2}{*}{2} & $\begin{array}{l}\text { Chodzieskie Lake } \\
\text { urban land }\end{array}$ & 17.06 .2004 & $\begin{array}{l}\text { Microcystis } \\
\text { Anabaena } \\
\text { Leptolyngbya }\end{array}$ & + & + & + & Microcystis & \\
\hline & & 01.07 .2004 & + & + & + & + & Microcystis & \\
\hline 3 & $\begin{array}{l}\text { Ciemino Lake } \\
\text { forestry land }\end{array}$ & 09.08 .2002 & $\begin{array}{l}\text { Synechococcus } \\
\text { Phormidium }\end{array}$ & + & - & - & & \\
\hline 4 & $\begin{array}{l}\text { Dobre Lake } \\
\text { forestry land }\end{array}$ & 20.08 .2004 & $\begin{array}{l}\text { Merismopedia } \\
\text { Leptolyngbya }\end{array}$ & + & - & - & & \\
\hline
\end{tabular}




\begin{tabular}{|c|c|c|c|c|c|c|c|c|}
\hline \multirow{2}{*}{ No. } & \multirow{2}{*}{$\begin{array}{l}\text { Name and nature of } \\
\text { water bodies }\end{array}$} & \multirow{2}{*}{$\begin{array}{l}\text { Date of } \\
\text { sampling }\end{array}$} & \multicolumn{5}{|l|}{$\begin{array}{l}\text { Presence of } \\
\text { cyanobacteria }\end{array}$} & \multirow{2}{*}{$\begin{array}{l}\text { Microcystin's concentration } \\
\text { Sampling Date } \\
\text { (References) }\end{array}$} \\
\hline & & & $\begin{array}{l}\text { Microscopic } \\
\text { observation }\end{array}$ & $\begin{array}{l}\mathrm{PCR} \\
\text { rpoC1 }\end{array}$ & $\begin{array}{l}\text { PCR } \\
m c y E\end{array}$ & $\begin{array}{l}\mathrm{PCR} \\
m c y B\end{array}$ & $\begin{array}{l}\text { Identification of } \\
\text { potentially toxic } \\
\text { cyanobacteria }\end{array}$ & \\
\hline 5 & $\begin{array}{l}\text { Dolsko Lake } \\
\text { forestry and agricultu- } \\
\text { ral land }\end{array}$ & 09.08.2002 & $\begin{array}{l}\text { Synechocystis } \\
\text { Cyanobium } \\
\text { Phormidium }\end{array}$ & + & - & - & & \\
\hline 6 & $\begin{array}{l}\text { Jeleń Lake } \\
\text { agricultural land }\end{array}$ & 09.08.2002 & $\begin{array}{l}\text { Oscillatoria } \\
\text { Anabaena }\end{array}$ & + & - & - & & \\
\hline \multirow[t]{4}{*}{7} & \multirow{4}{*}{$\begin{array}{l}\text { Jelonek Lake } \\
\text { agricultural land }\end{array}$} & 28.07.2003 & - & - & - & - & & \\
\hline & & 11.08 .2003 & + & + & - & - & & \\
\hline & & 10.10 .2003 & - & - & - & - & & \\
\hline & & 10.07.2004 & $\begin{array}{l}\text { Microcystis } \\
\text { Synechococcus } \\
\text { Nostoc }\end{array}$ & + & + & + & n.i. & \\
\hline \multirow[t]{2}{*}{8} & \multirow[t]{2}{*}{$\begin{array}{l}\text { Karlikowskie Lake } \\
\text { agricultural and urban } \\
\text { land }\end{array}$} & 10.07.2004 & $\begin{array}{l}\text { Microcystis, } \\
\text { Anabaena }\end{array}$ & + & + & + & n.i. & $\begin{array}{l}1-5 \mu \mathrm{g} / \mathrm{L} \\
08 / 27.08 .2003 \\
\text { (Mazur-Marzec, 2006) }\end{array}$ \\
\hline & & 17.07.2004 & + & + & + & + & n.i. & \\
\hline 9 & $\begin{array}{l}\text { Kamienickie Lake } \\
\text { agricultural and fore- } \\
\text { stry land }\end{array}$ & 25.07.2004 & Microcystis & + & - & - & Microcystis & \\
\hline \multirow[t]{3}{*}{10} & \multirow{3}{*}{$\begin{array}{l}\text { Kielno Lake } \\
\text { agricultural land }\end{array}$} & 20.07.2003 & + & + & + & + & n.i. & \multirow{3}{*}{$\begin{array}{l}<1 \mu \mathrm{g} / \mathrm{L} \\
29.08 .2003 \\
\text { (Mazur-Marzec, 2006) }\end{array}$} \\
\hline & & 10.08.2003 & + & + & + & + & n.i. & \\
\hline & & 10.10 .2003 & + & + & + & + & Microcystis & \\
\hline \multirow[t]{3}{*}{11} & \multirow[t]{3}{*}{$\begin{array}{l}\text { Klasztorne Duże Lake } \\
\text { urban land }\end{array}$} & 10.07.2003 & $\begin{array}{l}\text { Microcystis, } \\
\text { Planktothrix } \\
\text { Pseudanabaena }\end{array}$ & + & + & + & $\begin{array}{l}\text { Microcystis, Plank- } \\
\text { tothrix }\end{array}$ & $\begin{array}{l}1-5 \mu \mathrm{g} / \mathrm{L} \\
27.08 .2003,4.09 .2003 \\
\text { (Mazur-Marzec, 2006) }\end{array}$ \\
\hline & & 19.09.2003 & + & + & + & + & Planktothrix & \\
\hline & & 09.10 .2003 & + & + & + & + & Microcystis & \\
\hline \multirow[t]{2}{*}{12} & \multirow[t]{2}{*}{$\begin{array}{l}\text { Krąg Lake } \\
\text { agricultural land }\end{array}$} & 11.08 .2003 & $\begin{array}{l}\text { Microcystis, } \\
\text { Anabaena }\end{array}$ & + & + & + & Microcystis & \\
\hline & & 29.08 .2004 & + & + & + & + & n.i. & \\
\hline 13 & $\begin{array}{l}\text { Mausz Lake } \\
\text { agricultural and fore- } \\
\text { stry land }\end{array}$ & 06.07 .2004 & $\begin{array}{l}\text { Microcystis } \\
\text { Anabaena Lep- } \\
\text { tolyngbya }\end{array}$ & + & + & - & & \\
\hline \multirow[t]{4}{*}{14} & \multirow[t]{4}{*}{$\begin{array}{l}\text { Ostrzyckie Lake } \\
\text { agricultural and fore- } \\
\text { stry land }\end{array}$} & 31.07 .2003 & $\begin{array}{l}\text { Planktothrix } \\
\text { Microcystis } \\
\text { Anabaena }\end{array}$ & + & + & + & n.i. & \\
\hline & & 11.08 .2003 & + & + & + & + & Planktothrix & \\
\hline & & 09.09.2003 & + & + & + & + & Planktothrix & \\
\hline & & 09.10 .2003 & + & + & + & + & n.i. & \\
\hline \multirow[t]{5}{*}{15} & \multirow[t]{5}{*}{$\begin{array}{l}\text { Raduńskie Dolne Lake } \\
\text { agricultural and fore- } \\
\text { stry land }\end{array}$} & 31.07 .2003 & $\begin{array}{l}\text { Synechococcus } \\
\text { Pseudanabaena } \\
\text { Anabaena Mi- } \\
\text { crocystis }\end{array}$ & + & + & + & n.i. & \\
\hline & & 11.08 .2003 & + & + & + & + & $\begin{array}{l}\text { Planktothrix } \\
\text { Anabaena }\end{array}$ & \\
\hline & & 09.09.2003 & + & + & - & + & n.i. & \\
\hline & & 09.10 .2003 & + & - & - & - & & \\
\hline & & 17.07.2004 & + & + & - & + & n.i. & \\
\hline \multirow[t]{4}{*}{16} & \multirow{4}{*}{$\begin{array}{l}\text { Straszyn Lake } \\
\text { agricultural and urban } \\
\text { land }\end{array}$} & 31.07 .2003 & + & + & + & + & n.i. & \\
\hline & & 11.08 .2003 & - & - & - & - & & \\
\hline & & 09.09.2003 & - & + & - & - & & \\
\hline & & 09.10 .2003 & - & + & - & - & & \\
\hline
\end{tabular}




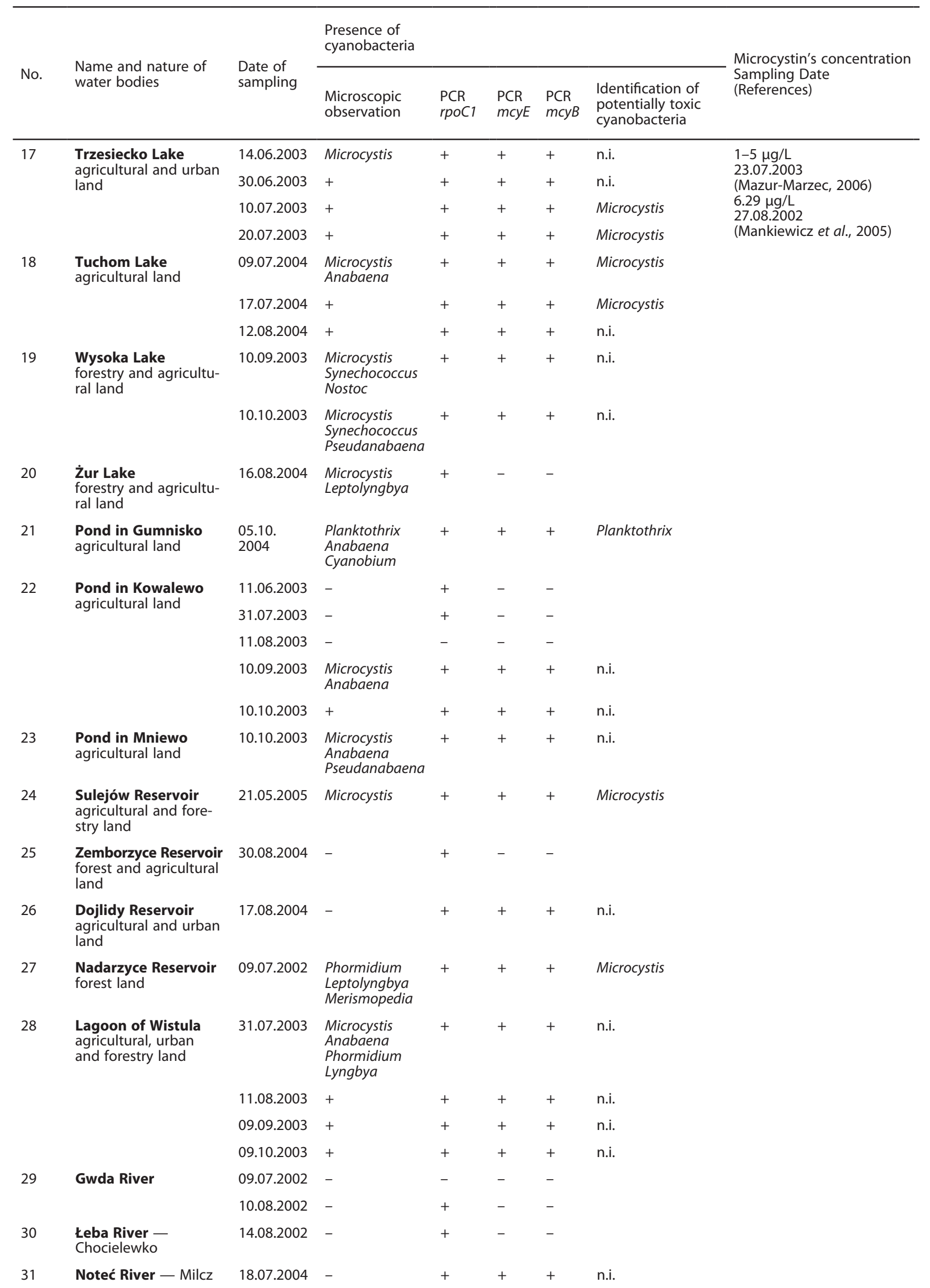




\begin{tabular}{|c|c|c|c|c|c|c|c|c|}
\hline \multirow{2}{*}{ No. } & \multirow{2}{*}{$\begin{array}{l}\text { Name and nature of } \\
\text { water bodies }\end{array}$} & \multirow{2}{*}{$\begin{array}{l}\text { Date of } \\
\text { sampling }\end{array}$} & \multicolumn{5}{|l|}{$\begin{array}{l}\text { Presence of } \\
\text { cyanobacteria }\end{array}$} & \multirow{2}{*}{$\begin{array}{l}\text { Microcystin's concentratior } \\
\text { Sampling Date } \\
\text { (References) }\end{array}$} \\
\hline & & & $\begin{array}{l}\text { Microscopic } \\
\text { observation }\end{array}$ & $\begin{array}{l}\text { PCR } \\
\text { rpoC1 }\end{array}$ & $\begin{array}{l}\text { PCR } \\
\text { mcyE }\end{array}$ & $\begin{array}{l}\text { PCR } \\
\text { mcyB }\end{array}$ & $\begin{array}{l}\text { Identification of } \\
\text { potentially toxic } \\
\text { cyanobacteria }\end{array}$ & \\
\hline \multirow[t]{4}{*}{32} & \multirow{4}{*}{$\begin{array}{l}\text { Radunia River - } \\
\text { Somonino }\end{array}$} & 31.07 .2003 & - & + & - & - & & \\
\hline & & 11.08 .2003 & - & - & - & - & & \\
\hline & & 09.09 .2003 & - & - & - & - & & \\
\hline & & 09.10 .2003 & - & - & - & - & & \\
\hline 33 & $\begin{array}{l}\text { Słupia River - } \\
\text { Soszyca }\end{array}$ & 20.09.2004 & - & - & - & - & & \\
\hline 34 & Tralalka River & 01.08 .2002 & - & - & - & - & & \\
\hline \multirow[t]{5}{*}{35} & $\begin{array}{l}\text { Gulf of Gdańsk - } \\
\text { Orłowo }\end{array}$ & 10.09 .2003 & Anabaena & + & - & - & & \\
\hline & & $\begin{array}{l}10.10 \\
2003\end{array}$ & - & + & - & - & & \\
\hline & $\begin{array}{l}\text { Gulf of Gdańsk - } \\
\text { Puck }\end{array}$ & 04.08 .2004 & + & + & - & - & & \\
\hline & $\begin{array}{l}\text { Gulf of Gdańsk - } \\
\text { Gdynia }\end{array}$ & $\begin{array}{l}10.08 \\
2002\end{array}$ & - & + & - & - & & \\
\hline & $\begin{array}{l}\text { Gulf of Gdańsk - } \\
\text { Osłonino }\end{array}$ & 16.08 .2004 & $\begin{array}{l}\text { Merismopedia } \\
\text { Aphanothece }\end{array}$ & + & - & - & & \\
\hline \multirow[t]{2}{*}{36} & $\begin{array}{l}\text { Baltic Sea - } \\
\text { Orzechowo }\end{array}$ & 31.07 .2003 & - & + & - & - & & \\
\hline & $\begin{array}{l}\text { Baltic Sea - } \\
\text { Rowy }\end{array}$ & 31.07 .2003 & - & - & - & - & & \\
\hline
\end{tabular}

lake the presence was between July and August, in Raduńskie Dolne lake between July and September (Table 1, Fig. 1). In the pond in Kowalewo, both genes were detected in October and September ( $\mathrm{Ta}$ ble 1, Fig. 1).

However, in samples isolated from eight water bodies (Bielsko, Ciemino, Dobre, Dolsko, Jeleń, Kamienickie, Zur, reservoir in Zemborzyce) and from four rivers (Gwda, Leba, Słupia, Tralalka) as well as from the Gulf of Gdańsk, in which rpoC1 gene was detected, the pres-
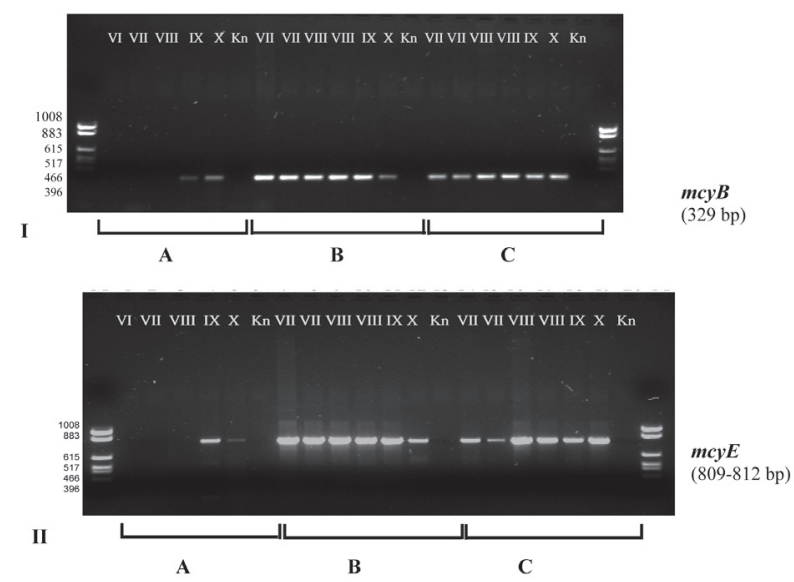

Figure 1. Detection of potentially toxic cyanobacteria in water samples collected periodically from three water bodies.

(A) pond in Kowalewo, (B) Klasztorne Duze Lake, (C) Lagoon of Wistula. Electrophoresis was performed in $1.2 \%$ agarose gel. I, detection of $m c y B$ gene fragment. II, detection of mcyE gene fragment. Roman figures represent the month, in which samples were collected. Kn, negative control. M, marker: pKO3/Hinfl. ence of genes involved in biosynthesis of microcystin was not observed (Table 1).

\section{Identification of cyanobacteria using clone library analysis}

To determine the composition of cyanobacteria communities in selected water bodies in which blooms appeared and to compare them with those in which mass occurrence of cyanobacteria was not observed, clone libraries were generated for seven water samples ( $\mathrm{Ta}$ ble 2).

The analysis of the clone libraries of the seven selected reservoirs indicated the presence of cyanobacteria belonging to genera Microcytis, Planktothrix, Synechococcus, Cyanobium, Anabaena and Woronichinia (Table 2). Strains from the genus Microcystis were the most prominent (186 clones out of 528 ) in the clone libraries. $\mathrm{Mi}$ crocystis-related genotypes, $4 \mathrm{M}$ and $5 \mathrm{M}$, constituted $35 \%$ of all tested clones (Fig. 2, Table 2). The genotype 5M was dominant and the most widespread and was observed in 6 out of 7 analyzed water bodies, besides the pond in Gumnisko in which three different genotypes of Planktothrix were accrued (Table 2).

One-hundred and forty-six out of $528(27.6 \%)$ clone sequences exhibited the highest level of similarity with $16 \mathrm{~S}$ rDNA sequences of Planktothrix. For this genus of cyanobacteria 4 different genotypes were discriminated, $12 \mathrm{M}, 13 \mathrm{M}, 14 \mathrm{M}$ and $16 \mathrm{M}$ (Fig. 2, Table 2). The genus Planktothrix was abundant in two lakes, Klasztorne Duże and Ostrzyckie, and one pond in Gumnisko (Table 2). Cyanobacteria from the genus Planktothrix strongly dominated the cyanobacterial community in two water bodies, the Gumnisko pond and Ostrzyckie Lake, in which 
Table 2. Identification of cyanobacteria on the basis of sequences obtained from the rrn clone library

\begin{tabular}{|c|c|c|c|c|}
\hline \multirow{2}{*}{ Reservoirs } & \multirow{2}{*}{$\begin{array}{l}\text { Number } \\
\text { of clones }\end{array}$} & \multirow{2}{*}{$\begin{array}{l}\text { Genotype on the } \\
\text { basis of } 16 \mathrm{~S} \text { rDNA }\end{array}$} & \multicolumn{2}{|l|}{ Blast Relatives } \\
\hline & & & Name of closest relatives & $\operatorname{Max}_{\mathrm{id}}$ \\
\hline \multirow{4}{*}{$\begin{array}{l}\text { Pond in Drzewce* } \\
(15.09 .2004)\end{array}$} & 46 & $5 M$ & Microcystis sp. & $99 \%$ \\
\hline & 14 & $10 \mathrm{M}$ & Anabaena sp. & $91 \%$ \\
\hline & 7 & $9 \mathrm{M}$ & Anabaena sp. & $97 \%$ \\
\hline & 5 & $4 \mathrm{M}$ & Microcystis sp. & $96 \%$ \\
\hline \multirow{4}{*}{$\begin{array}{l}\text { Pond in Gumnisko* } \\
(02.09 .2004)\end{array}$} & 29 & $14 \mathrm{M}$ & Planktothrix sp. & $98 \%$ \\
\hline & 23 & $12 \mathrm{M}$ & Planktothrix sp. & $98 \%$ \\
\hline & 5 & $15 \mathrm{M}$ & Cyanobium sp. & $99 \%$ \\
\hline & 4 & $16 \mathrm{M}$ & Planktothrix sp. & $99 \%$ \\
\hline \multirow{3}{*}{$\begin{array}{l}\text { Klasztorne Duże Lake** } \\
(09.10 .2003)\end{array}$} & 63 & $5 \mathrm{M}$ & Microcystis sp. & $99 \%$ \\
\hline & 10 & $16 \mathrm{M}$ & Planktothrix sp. & $99 \%$ \\
\hline & 5 & $12 \mathrm{M}$ & Planktothrix sp. & $98 \%$ \\
\hline \multirow{6}{*}{$\begin{array}{l}\text { Ostrzyckie Lake }{ }^{* * *} \\
(11.08 .2003)\end{array}$} & 44 & $12 \mathrm{M}$ & Planktothrix sp. & $98 \%$ \\
\hline & 23 & $13 \mathrm{M}$ & Planktothrix sp. & $98 \%$ \\
\hline & 3 & $5 \mathrm{M}$ & Microcystis sp. & $99 \%$ \\
\hline & 6 & $11 \mathrm{M}$ & Woronichinia sp. & $99 \%$ \\
\hline & 5 & $14 \mathrm{M}$ & Planktothrix sp. & $98 \%$ \\
\hline & 2 & $10 \mathrm{M}$ & Anabaena sp. & $91 \%$ \\
\hline \multirow{4}{*}{$\begin{array}{l}\text { Raduńskie Dolne*** } \\
\text { Lake } \\
(11.08 .2003)\end{array}$} & 44 & $2 M$ & Synechococcus sp. & $98 \%$ \\
\hline & 9 & $1 \mathrm{M}$ & Synechococcus sp. & $93 \%$ \\
\hline & 8 & $9 M$ & Anabaena sp. & $97 \%$ \\
\hline & 7 & $5 \mathrm{M}$ & Microcystis sp. & $99 \%$ \\
\hline \multirow{6}{*}{$\begin{array}{l}\text { Wysoka Lake*** } \\
(10.09 .2003)\end{array}$} & 61 & $11 \mathrm{M}$ & Woronichinia sp. & $99 \%$ \\
\hline & 14 & $5 \mathrm{M}$ & Microcystis sp. & $99 \%$ \\
\hline & 7 & $6 \mathrm{M}$ & Synechococcus sp. & $99 \%$ \\
\hline & 5 & $1 \mathrm{M}$ & Synechococcus sp. & $93 \%$ \\
\hline & 2 & $7 \mathrm{M}$ & Synechocystis sp. & $99 \%$ \\
\hline & 2 & $8 M$ & Synechococcus sp. & $92 \%$ \\
\hline \multirow{8}{*}{$\begin{array}{l}\text { Jelonek Lake }{ }^{* * * *} \\
(11.08 .2003)\end{array}$} & 45 & $5 \mathrm{M}$ & Microcystis sp. & $99 \%$ \\
\hline & 9 & $6 \mathrm{M}$ & Synechococcus sp. & $99 \%$ \\
\hline & 6 & $15 \mathrm{M}$ & Cyanobium sp. & $99 \%$ \\
\hline & 3 & $17 \mathrm{M}$ & n.i. & No data \\
\hline & 3 & $18 \mathrm{M}$ & Synechococcus sp. & $99 \%$ \\
\hline & 3 & $3 M$ & Synechococcus sp. & $90 \%$ \\
\hline & 3 & $4 M$ & Microcystis sp. & $96 \%$ \\
\hline & 3 & $16 \mathrm{M}$ & Planktothrix sp. & $99 \%$ \\
\hline
\end{tabular}

*Reservoirs with bloom of cyanobacteria; ${ }^{* *}$ Samples were collected 2 months after bloom; ***Reservoirs, in which bloom was not observed during specimen collection

they constituted about $86.7 \%$ and $91.8 \%$, respectively (Table 2).

\section{DISCUSSION}

In this study, the presence and identification of cyanobacteria in Polish waterbodies was verified using microscopic observation, standard PCR methods and clone libraries constructed for environmental samples. Most of the studied waterbodies are under an excessive nutrient loading from agricultural, industrial and urban runoff, in effect many of them are eutrophicated (Table 3).

Microscopic observation allowed detecting of cyanobacteria in $63(72.4 \%)$ samples, while amplification of $r p o C 1$ gene specific for cyanobacteria allowed for detection of this group of bacteria in $75(86.2 \%)$ samples (Table 1). These results indicate the high value of $r p o C 1$ PCR method for detection of cyanobacteria in environmental samples. The usefulness of the $r_{0} \mathrm{Cl}$ gene fragment as a molecular marker for detection, identification 


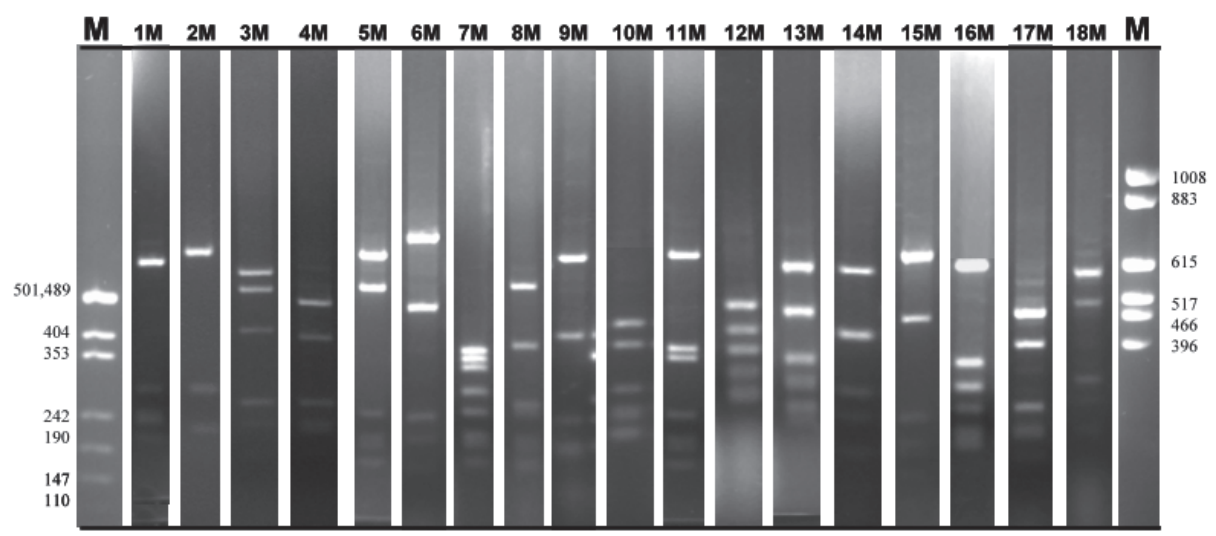

Figure 2. RFLP genotypes discriminated on the basis of Mspl restriction endonuclease digestion of amplified rrn operon fragments of 533 clones

Electrophoresis was performed in $2 \%$ agarose gel in TEA buffer. Molecular marker $\left(M_{\text {left }}\right) M s p l / p U C 18 D N A,\left(M_{\text {right }}\right)$ pKO3/Hinfl. Figure was created using BioNumerics program. and differentiation of cyanobacteria has previously been described (Toledo \& Palenik, 1997; Jameson et al., 2008; Yoshida et al., 2008; Valério et al., 2009; Han et al., 2009).

The results of microscopic observation were in general agreement with the molecular data. However, in the case of samples collected from Raduńskie Dolne Lake (October 2003), cyanobacteria were observed under the

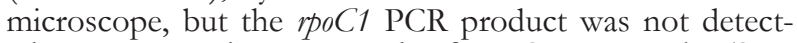
ed. In contrast, in two samples from Straszyn Lake (September 2003; October 2003), we did not see any cells of cyanobacteria during microscopic observation, but we got $r p_{0}$ C1 PCR products (Table 1). The procedure of sampling (filtration of water samples using filters) allowed checking the presence of cyanobacteria cells in a large volume of water sample and thus facilitated the generation of the specific PCR product.

Because microcystins are most widespread cyanotoxins, we focused on the detection of cyanobacteria that have the genetic potential to produce these toxins. In all water blooms investigated in this study, PCR amplification of $m y B$ and $m y E$ genes confirmed the presence of these genes in the environment (Table 1). According to these results, we concluded that 7 analyzed blooms were potentially toxic and contained Microcystis and Planktothrix cells. Only moy gene was detected in Bnińskie and Bytyńskie Lake. This indicates that potentially toxic Planktothrix strains were present in these lakes (Table 1).

It is worth to emphasize that the presence of microcystins-related genes $(m c y B$ and $m c y E)$ is not a proof of the occurrence of the toxins, but only shows, that potentially toxic cyanobacteria are present in the tested water bodies. Some strains may have only fragments of the my genes cluster or mutations within these genes, and in spite of being a source of DNA for successful amplification with primers specific for moy genes, they are not toxin-producers (Vaitomaa et al., 2003). Earlier studies (Rantala et al., 2004; Mankiewicz-Boczek et al., 2006) have indicated that the myE gene is the best molecular marker for the determination of potentially toxic cyanobacteria in environmental samples. The detection of a myE PCR product means that potentially toxic cyanobacteria are present in the sample, because this gene encodes modules responsible for incorporation of 3-amino-9-methoxy-2,6,8-trimethyl-10-phenyl4,6-decadienoic acid, (Adda) and D-glutamate into the microcystin molecules. These two amino acids are crucial for toxicity, and moreover they vary less than the other amino acids comprising the many toxin isoforms (Sivonen \& Jones, 1999). Mankiewicz-Boczek et al. (2006) tested primers for amplification of $m c y A, m c y B$, $m c y$ and $m y E$, and showed that the $m c y E$ gene frag- ment was amplified in all water samples containing different genera of microcystins-producing cyanobacteria. The next most frequently amplified gene was $\operatorname{my} B$ (in $96 \%$ of tested water samples). However, in the cited publications another $m c y B$ gene fragment was applied and other primers were used.

An overwhelming majority of the selected water bodies were examined for the first time, however, seven of them had previously been examined by others by biochemical, physicochemical (Table 3) and partly molecular methods and can serve as a control for the results obtained by the applied molecular analysis.

The combination of microscopic and molecular analyses of the sample collected from Bnińskie Lake indicated that bloom (observed in September 2004) was caused by cyanobacteria belonging to genus Planktothrix (Table 1). This result is in accordance with previous investigations of this lake indicating toxic cyanobacteria dominated by Planktothrix agardhii (Mankiewicz-Boczek et al., 2006; 2009). Mankiewicz-Boczek (2006) determined the toxicity of the water samples collected from Bnińskie Lake in September 2004, using protein phosphatase inhibition assay (PPIA) and high performance liquid chromatography (HPLC). Microcystin concentration estimated by HPLC was $10.47 \mu \mathrm{g} / \mathrm{L}$. A compilation of literature and our data confirms that cyanobacteria present in Bninskie Lake were not only potentially toxic, but also efficiently produced toxins.

Microscopic analysis of water samples collected from Klasztorne Duże Lake indicated Planktothrix and Microcystis strains. The amplification of $m c y B$ and $m c y E$ genes confirmed the presence of toxic cyanobacteria (Table 1). The clone library generated for samples collected from this lake two months after bloom showed that strains of Planktothrix and Microcystis were still dominant in this reservoir. Mazur-Marzec (2008) also identified strains of Planktothrix and Microcystis in this lake and estimated microcystin concentration at $1-5 \mu \mathrm{g} / \mathrm{L}$ during summer 2003. In accord with the results obtained by Mankiewicz et al. (2005) and Mazur-Marzec (2008) for Trzesiecko Lake in 2002 and 2003, our data indicated the presence of potentially toxic strains of Microcystis also in 2004. This suggests that the population of toxic Microcystis in this lake is stable.

In this study, the presence of Microcystis strains was reported in Tuchom Lake in summer 2003 and 2004. The PCR products of $r p o C 1, m c y B$ and $m y E$ genes confirmed the occurrence of potentially toxic Microcystis. MazurMarzec (2008) monitored Tuchom Lake during summer in 2000, 2001, 2002 and 2003. They detected the genera Microcystis and Anabaena, and the concentration of micro- 
Table 3. Physicochemical parameters of investigated lakes

\begin{tabular}{|c|c|c|c|c|c|}
\hline Name of water bodies & $\begin{array}{l}\text { Surface } \\
\left(\mathrm{km}^{2}\right)\end{array}$ & $\begin{array}{l}\text { Mean } \\
\text { depth (m) }\end{array}$ & $\begin{array}{l}\text { TP (mg P/L)a } \\
\text { Sampling date* }\end{array}$ & $\begin{array}{l}\text { TN (mg N/L)b } \\
\text { Sampling date* }\end{array}$ & $\begin{array}{l}\text { Chl-a }(\mu \mathrm{g} / \mathrm{L}) \mathrm{c} \\
\text { Sampling date* }\end{array}$ \\
\hline Bnińskie Lake & 2.215 & 4.2 & $0.207-10.2004^{1}$ & $2.307-10.2004^{1}$ & n.d \\
\hline Bytyńskie lake & 3.088 & 3.5 & $0.0922000^{2}, 2009^{3}$ & $2.952000^{2}, 2009^{3}$ & $47.32000^{2}, 2009^{3}$ \\
\hline Chodzieskie Lake & 1.15 & 3.1 & $0.1962000^{2}$ & $2.472000^{2}$ & $82.7112000^{2}$ \\
\hline Ciemino Lake & 2.417 & 6.0 & $0.11998^{4}, 2008^{5}$ & $1.41998^{4}, 2008^{5}$ & n.d. \\
\hline Dolskie Lake & 0.348 & 10 & $0.01907 .2003^{6}$ & $2.2607 .2003^{6}$ & n.d. \\
\hline Jeleń Lake & 0.89 & 12.0 & $\mathbf{0 . 0 7} 05-08.2006^{7}$ & $1.3505-08.2006^{7}$ & $\mathbf{2 - 5} 05-08.2006^{7}$ \\
\hline Karlikowskie Lake & 0.31 & 5.0 & $0.181998^{8}$ & $2.21998^{8}$ & n.d. \\
\hline Klasztorne Duże Lake & 0.57 & 8.0 & $0.262007^{12}$ & $2.502007^{12}$ & $108.92007^{12}$ \\
\hline Krąg Lake & 1.484 & 2.0 & $0.62002^{11}$ & $2.12002^{11}$ & \\
\hline Mausz Lake & 3.84 & 12.8 & $0.0512008^{13}$ & $1.0212008^{13}$ & $6.12008^{13}$ \\
\hline Ostrzyckie Lake & 3.08 & 6.7 & 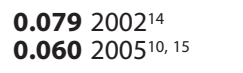 & $\begin{array}{l}\mathbf{0 . 7 4} 2002^{14} \\
\mathbf{0 . 9 0} 2005^{10,15}\end{array}$ & $\begin{array}{l}\mathbf{1 5 . 6} 2002^{14} \\
\mathbf{2 7 . 5} 2005^{10,15}\end{array}$ \\
\hline Raduńskie Dolne Lake & 11.2 & 7.372 & 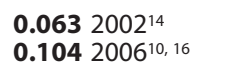 & 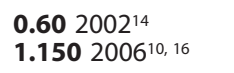 & $\begin{array}{l}10.42002^{14} \\
722006^{10,16}\end{array}$ \\
\hline Straszyn Lake & 0.75 & 5 & $\begin{array}{l}<0.12002^{14} \\
\mathbf{0 . 1 3} 2006{ }^{11}\end{array}$ & $\begin{array}{l}<0.12002^{14} \\
1.292006^{11}\end{array}$ & $152002^{14}$ \\
\hline Trzesiecko Lake & 2.95 & 5.4 & $0.1108 .2002^{17}$ & $2.5908 .2002^{7}$ & \\
\hline Wysoka (Wycztok) Lake & 0.55 & 1.9 & $0.05008 .2001^{18}$ & $1.1108 .2001^{18}$ & $57.708 .2001^{18}$ \\
\hline Sulejów Reservoir & 27 & 3.3 & $0.207-10.2004^{1}$ & $1.007-10.2004^{1}$ & n.d. \\
\hline Zemborzyce Reservoir & 2.8 & 2.5 & $0.3605-10.2003^{21}$ & $\begin{array}{l}\mathbf{0 . 0 7 5} \mathrm{NaNO}_{3} \\
\mathbf{0 . 3 3} \mathrm{N}^{-\mathrm{NH}_{4}} \\
05-10.200321\end{array}$ & $12905-10.2003^{21}$ \\
\hline Nadarzyce Reservoir & 2.027 & 4 & $0.052004^{4}$ & $<1.02004^{4}$ & $<8.02004^{4}$ \\
\hline Lagoon of Wistula & 838 & 2.4 & $\begin{array}{l}0.31607 .2007^{22} \\
\mathbf{0 . 2 6 3} 08.2008^{22}\end{array}$ & $\begin{array}{l}\mathbf{4 . 8} 08.2007^{22} \\
\mathbf{3 . 5 6} 07.2008^{2}\end{array}$ & $\begin{array}{l}142.206 .2007^{22} \\
145.907 .2008^{22}\end{array}$ \\
\hline Łeba River - Lębork Mosty & & & $0.112005^{23}$ & $1.862005^{23}$ & $2.12005^{23}$ \\
\hline Noteć River — Nakło & & & $0.242004^{20}$ & $1.962004^{20}$ & $25.32004^{20}$ \\
\hline Radunia River - Somonino & & & $\begin{array}{l}0.152001^{24} \\
0.12004^{25}\end{array}$ & $\begin{array}{l}1.52001^{24} \\
0.92004^{25}\end{array}$ & $72004(26)$ \\
\hline Słupia River - Charnowo & & & $0.112005^{23}$ & $2.012005^{23}$ & $3.72005^{23}$ \\
\hline Gulf of Gdańsk — Orłowo & & 6.5 & $0.0507 .2009^{26}$ & $0.44307 .2009^{26}$ & $\begin{array}{l}\mathbf{3 4 . 5} 07.2004^{27} \\
\mathbf{1 4 . 4} 07.2005^{27} \\
\mathbf{3 . 5 6} 07.2009^{26}\end{array}$ \\
\hline Gulf of Gdańsk — Puck & & 1.5 & $0.06407 .2009^{26}$ & $0.34407 .2009^{26}$ & $14.0107 .2009^{26}$ \\
\hline Gulf of Gdańsk — Gdynia & & 10.0 & $0.08907 .2009^{26}$ & $0.37507 .2009^{26}$ & $3.2907 .2009^{26}$ \\
\hline Gulf of Gdańsk — Osłonino & & 2.5 & $0.050907 .2009^{26}$ & $0.34907 .2009^{26}$ & $\mathbf{8 . 4 2} 07.2009^{26}$ \\
\hline Baltic Sea - Rowy & & 6.5 & $\mathbf{0 . 0 3 1} 06.2009^{26}$ & $1.1406 .2009^{26}$ & $106.2009^{26}$ \\
\hline
\end{tabular}

n.d., not determined; *if months of sampling are not specified the year average is stated; ${ }^{\mathrm{T} T P}$, total phosphorus; ${ }^{\mathrm{b} T N}$, total nitrogen; ${ }^{\mathrm{C}} \mathrm{Chl}-\mathrm{a}$, chlorophyll a; ${ }^{1}$ Mankiewicz-Boczek et al., $2006 ;{ }^{2}$ WIOŚ Poznań, 2000; ${ }^{3}$ WIOS Poznań, 2009; ${ }^{4}$ ABRYS Technika 2004; ${ }^{5}$ WIOŚ Szczecin, 2011; ${ }^{6}$ D. Borowiak (pers. com.); ${ }^{7}$ Witek \& Jarosiewicz, 2010; ${ }^{8}$ Gos \& Bociąg, 1998; ${ }^{9}$ Starostwo Powiatowe w Kartuzach, 2008; ${ }^{10}$ Borowiak, 2007; ${ }^{11}$ http://www.infoeko.pomorskie.pl/; 12WIOŚ Gdańsk, 2008; 13WIOŚ Gdańsk, 2009; 14WIOŚ Gdańsk, 2003; 15WIOŚ Gdańsk, 2006a; 16 WIOŚ Gdańsk, 2007; 17Mankiewicz et al., 2005; 18WIOŚ Gdańsk, 2002a; ${ }^{19}$ WIOŚ Bydgoszcz, 2002; 20WIOŚ Bydgoszcz, 2006; ${ }^{21}$ Pawlik-Skowrońska et al., 2004; 22 WIOŚ Olsztyn, 2008; 23 WIOŚ Gdańsk, 2006b; ${ }^{24}$ WIOŚ Gdańsk, 2002b; ${ }^{25}$ WIOŚ Gdańsk, 2005; ${ }^{26}$ WIOŚ Gdańsk, 2010; ${ }^{27}$ Mazur-Marzec et al., 2006. 
cystins ranged from 1 to $5 \mu \mathrm{g} / \mathrm{L}$ (Table 1 ). These results indicate the long-term occurrence of Microcystis in Tuchom Lake.

Analysis of water samples collected from Sulejów Reservoir, which is an alternative source of drinking water for the city of Lódź, demonstrated the presence of toxic cyanobacteria from genus Microcystis. This result confirmed the previous data describing the appearance of toxigenic cyanobacteria and their toxins in this reservoir (Jurczak et al., 2004; Izydorczyk et al., 2005; Palus et al., 2007; Gagała et al., 2010) and data revealing the microcystin concentration in September 2004 (Mankiewicz et al., 2006).

The microscopic identification of cyanobacteria in blooming ponds in Drzewce, Mniewo and Gumnisko indicated the presence of Microcystis strains in the first two ponds and Planktothrix strains in the third one. The presence of cyanobacteria with the genetic ability to produce toxins was confirmed by PCR tests (Table 1).

The presented results are the first application of rpoC1 gene for detection of cyanobacteria in samples from Polish water bodies. The data obtained through molecular analysis based on PCR amplifications of rpoC1, $m c y$ and $m y E$ genes turned out to be adequate for the detection of cyanobacteria including toxic strains and are in agreement with earlier studies obtained with other methods (Table1). A significant advantage of the application of molecular methods for the detection of cyanobacteria and their toxic strains is the fact that they allow prediction of the mass occurrence of potentially toxic cyanobacteria before the bloom appears. Janse et al. (2005) suggested that the strain that was present in very low abundance in wintertime was the same strain that would form a bloom in spring.

Some data indicate that toxic strains utilize more nutrients and grow better in eutrophic water bodies than nontoxic strains (Lee et al., 2000). For the first time, we studied water samples collected from ponds and small lakes in villages (ponds in Drzewce, Gumnisko, Mniewo, Kowalewo, and lakes Kielno and Krag). We intended to verify the appearance of potentially toxic cyanobacteria in water bodies being under the influence of agriculture and to determine the potential risk of using these waters. The obtained results indicated a mass occurrence of potentially toxic cyanobacteria in the ponds in Drzewce, Gumnisko and Mniewo in which blooms were observed each year but no informations about the presence of toxic cyanobacteria were available (Table 1). Cyanobacteria occurring in these waters were assigned to Microcystis and Planktothrix on the basis of microscopic and molecular evaluations. Microcystis strains were also detected in Kielno Lake and Krag Lake. In all these water bodies genes $m y B$ and $m y E$ were detected. On the basis of obtained results it can be concluded that all tested waterbodies, which were under the influence of agriculture, were contaminated by cyanobacteria able to produce microcystins (Table 1 and Table 3 ).

The investigation of water samples collected from reservoirs which are a source of drinking water for cities (Sulejów Reservoir and Straszyn Lake) also indicated the presence of potentially toxic cyanobacteria (Table 1). The obtained results support the earlier conclusions that this type of reservoirs should be carefully monitored for the presence of toxic cyanobacteria, especially when microcystin-related genes are present. The Sulejowski Reservoir is actually in constant monitoring for cyanobacteria, including physicochemical, genetic, biochemical and toxicological analyses (Jurczak et al., 2004; Izydorczyk et al., 2005; Mankiewicz-Boczek et al., 2006a; 2006b; Palus et al., 2007, Izydorczyk et al., 2008; Gagała et al., 2010).

The detection of cyanobacteria in running waters turned out to be difficult. We analyzed 10 samples collected from 6 rivers (Radunia, Gwda, Leba, Noteć, Slupia, Tralalka). Positive results of the $r p o C 1$ PCR amplification were obtained for four samples (Table 1). The occurrence of potentially toxic cyanobacteria was revealed only in one sample from the Noteć. In that case the sampling point was located on a lowland area with a very slow water flow and the river was eutrophicated in this area (Table 3).

The identification of cyanobacteria was conducted using clone libraries constructed from environmental DNA samples from five selected lakes and two ponds (Table 2). In the Drzewce Pond, we detected cyanobacteria assigned to genera Microcystis and Anabaena. In Gumnisko Pond, Planktothrix and Cyanobium were identified (Table 2). Results demonstrated a lower diversity of cyanobacteria in reservoirs in which blooms were present. Lower biodiversity of cyanobacteria was also found in Klasztorne Duże Lake, which was investigated two months after a bloom. According to our knowledge, this is the first comprehensive study concerning cyanobacteria and their toxigenic strains present in different types of Polish water bodies (Table 1 and Table 3) performed using molecular markers.

\section{CONCLUSIONS}

The high effectiveness of the molecular marker $r p o C 1$ for the detection of cyanobacteria was illustrated. Applied molecular markers $m y B$ and $m c y E$ allowed the detection of potentially toxic cyanobacteria in Polish water bodies. The present results indicate that potentially toxic cyanobacteria occur widely in reservoirs, lakes and ponds of Poland. Our results confirm the usefulness of the selected cyanobacterial genes for monitoring water bodies and rapid detection of potentially toxic cyanobacteria. Application of molecular methods allows one to choose a group of water bodies that have the potential to form toxic blooms and have to be monitored. The described procedure is applicable for the prediction of the occurrence of toxic blooms before they actually happen.

\section{Acknowledgements}

This work was supported by grants: KBN 0365/ P042003/24, MNiSW 1682/Po1/2007/32.

The authors wish to thank Dr. Annick Wilmotte for critical reading and helpful comments and suggestions.

\section{REFERENCES}

ABRYS Technika Sp. z o.o. (2004) Analysis and evaluation of resources and environmental components. Environment Programme for the Municipal Council Borne Sulinowo.

Azavedo SM, Carmichael WW, Jochimsen EM, Rinehart KL, Lau S, Shaw GR, Eaglesham GK (2002) Human intoxication by microcystins during renal dialysis treatment in Caruaru-Brazil. Toxicology 181-182: 441-446.

Bergsland KJ, Haselkorn R (1991) Evolutionary relationships among eubacteria, cyanobacteria, and chloroplasts: evidence from the rpoC1 gene of Anabaena sp. strain PCC 7120. J Bacteriol 173: 34463455.

Borowiak D (2007) Atlas of the Kashubian Landscape Park Lakes. Ser Bad Limnol 4: pp 61, 225, 239. KLUG, Gdańsk.

Burja AM, Banaigs B, Abou-Mansour E, Burgess JG and Wright PC (2001) Marine cyanobacteria - a prolific source of natural products. Tetrabedron 57: 9347-9377. 
Chen J, Zhang D, Xie P, Wang Q, Ma Z (2009) Simultaneous determination of microcystin contaminations in various vertebrates (fish, turtle, duck and water bird) from a large eutrophic Chinese lake, Lake Taihu, with toxic Microcystis blooms. Sci Total Environ 407: 3317-3322.

Codd GA, Lindsay J, Young FM, Morrison LF, Metcalf JS (2005) Harmful cyanobacteria: from mass mortalities to management measures. In Harmful cyanobacteria. Huisman J, Matthijs HCP, Visse PM, eds, pp 1-24. Springer, Dordrecht, The Netherlands.

Codd GA, Metcalf JS, Morrison LF, Krienitz L, Ballot A, Pflugmacher S, Wiegand C, Kotut K (2003) Susceptibility of flamingos to cyanobacterial toxins via feeding. Vet Rec 152: 722-723.

Gagała I, Izydorczyk K, Skowron A, Kamecka-Plaskota D, Stefaniak K, Kokociński M, Mankiewicz-Boczek J (2010) Appearance of toxigenic cyanobacteria in two Polish lakes dominated by Microcystis aeruginosa and Planktothrix agardhii and environmental factors influence. Ecobydrology \& Hydrobiology 10: 25-34.

Gos K, Bociang K (1998) Lobelia lakes trail - a description of the trip. In: Vegetation of Pomerania, Diversity, Dynamics, Risks, Protection. Herbich J, Herbichowa M, eds, pp 245-248. Wyd UG Gdańsk.

Han, D, Fan, Y, Hu, Z (2009) An evaluation of four phylogenetic markers in Nostoc: implications for cyanobacterial phylogenetic studies at the intrageneric level. Curr Microbiol 58: 170-176.

Ha JH, Hidaka T, Tsuno H (2009) Quantification of toxic Microcystis and evaluation of its dominance ratio in blooms using real-time PCR. Environ Sci Technol 43: 812-818.

http://www.infoeko.pomorskie.pl/. Homepage of Centre of Information, and Ecological Education in Gdansk.

Hisbergues M, Christiansen G, Rouhiainen L, Sivonen K, Borner T (2003) PCR-based identification of microcystin-producing genotypes of different cyanobacterial genera. Arch Microbiol 180: 402-410.

Janse I, Kardinaal WE, Agterveld MK, Meima M, Visser PM, Zwart G (2005) Contrasting microcystin production and cyanobacterial population dynamics in two Planktothrix-dominated freshwater lakes. Environ Microbiol 7: 1514-1524.

Jurczak T, Tarczyńska M, Karlsson K, Meriluoto J (2004) Characterization and diversity of cyanobacterial hepatotoxins (microcystins) in blooms from Polish freshwaters identified by liquid chromatography - Electrospray Ionisation Mass Spectrometry. Chromatographia 59: $571-578$

Izydorczyk K, Tarczynska M, Jurczak T, Mrowczynski J, Zalewski M (2005) Measurement of phycocyanin fluorescenceas an online early warning system for cyanobacteria in reservoir intake water. Environ Toxicol 20: 425-430.

Kobos J, Mazur-Marzec H, Dittmer M, Witek B, Plinski M (2005) Toxic cyanobacterial blooms in the Kociewskie Lakes (Northern Poland). Oceanological and Hydrobiological Studies 34: 77-84.

Kreitlow S, Mundt S, Lindequist U (1999) Cyanobacteria - a potential source of new biologically active substances. I Biotechnol 70: 61-63.

Lee SI, Jang MH, Kim HS, Yoon BD, Oh HM (2000) Variation of microcystin content of Microcystis aeruginosa relative to medium N:P ratioand growth stage. I Appl Microbiol 89: 323-329.

Mankiewicz J, Komárková J, Izydorczyk K, Jurczak T, Tarczynska M, Zalewski M (2005) Hepatotoxic cyanobacterial blooms in the lakes of northern Poland. Environ Toxicol 20: 499-506.

Mankiewicz-Boczek J, Izydorczyk K, Romanowska-Duda Z, Jurczak T, Stefaniak K, Kokocinski M (2006) Detection and monitoring toxigenicity of cyanobacteria by application of molecular methods. Environ Toxicol 21: 380-387.

Mankiewicz-Boczek J, Gagała I, Kokociński M, Jurczak T, Stefaniak K (2009) Perennial toxigenic Planktothrix agardhii bloom in selected lakes of Western Poland. Environ Toxicol Aug 5, DOI: 10.1002/ tox. 20524 .

Mazur-Marzec H, Krężel A, Kobos J, Pliński M (2006) Toxic Nodularia spumigena blooms in the coastal waters of the Gulf of Gdańsk: a ten-year survey. Oceanologia 48: 255-273.

Mazur-Marzec H, Spoof L, Kobos J, Plinski M, Meriluoto J (2008) Cyanobacterial hepatotoxins, microcystins and nodularins, in fresh and brackish waters of the Pomeranian Province, northern Poland. Oceanol Hydrobiol Studies 37: 3-21.

Nonneman D, Zimba PV (2002) A PCR-based test to assess the potential for microcystin occurrence in channel catfish production ponds. I Phycol 38: 230-233.

Nübel U, Garcia-Pichel F, Muyzer G (1997) PCR primers to amplify $16 \mathrm{~S}$ rRNA genes from cyanobacteria. Appl Environ Microbiol 63: 3327-3332.

Otsuka S, Suda S, Li R, Matsumoto S, Watanabe MM (2000) Morphological variability of colonies of Microcystis morphospecies in culture. J Gen Appl Microbiol 46: 39-50.

Ouellette AJ, Handy SM, Wilhelm SW (2005) Toxic Microcystis is widespread in Lake Erie: PCR detection of toxin genes and molecular characterization of associated cyanobacterial communities. Microb Ecol 51: 154-65.

Palinska, KA, Liesack W, Rhiel E, Krumbein WE (1996) Phenotype variability of identical genotypes: the need for a combined approach in cyanobacterial taxonomy demonstrated on Merismopedia - like isolates. Arch Microbiol 166: 224-233.

Palus J, Dziubaltowska E, Stanczyk M, Lewinska D, Mankiewicz-Boczek J, Izydorczyk K, Bonislawska A, Jurczak T, Zalewski M, Wasowicz W (2007) Biomonitoring of cyanobacterial blooms in Polish water reservoir and the cytotoxicity and genotoxicity of selected cyanobacterial extracts. Int J Occup Med Environ Health 20: 48-65.

Pawlik-Skowrońska B, Skowroński T, Pirszel J, Adamczyk A (2004) Relationship between cyanobacterial bloom composition and anatoxin-a and microcystinoccurrence in the eutrophicdam reservoir (SE Poland). Pol J Ecol 52: 479-490.

Pearson LA, Neilan BA (2008) The molecular genetics of cyanobacteria toxicity as a basis for minitoring water quality and public health risk. Curr Opin Biotechnol 19: 281-288.

Rantala A, Fewer DP, Hisberoues M, Rouhiainen L, Vaitomaa J, Borner T, Sivonen K (2004) Phylogenetic evidence for the early evolution of microcystin synthesis. Proc Natl Acad Sci USA 101: 568-573.

Rippka R (1988) Isolation and purification of cyanobacteria. Methods Ensymol 167: 3-28.

Rouhiainen L, Sivonen K, Buikema WJ, Haselkorn R (1995) Characterization of toxin-producing cyanobacteria by using an oligonucleotide probe containing a tandemly repeated heptamer. I Bacteriol 177: 6021-6026.

Rouhiainen L, Vakkilainen T, Siemer BL, Buikema W, Haselkorn R, Sivonen K (2004) Genes coding for hepatotoxic heptapeptides (microcystins) in the cyanobacterium Anabaena strain 90. Appl Environ Microbiol 70: 686-692.

Sivonen K (1996) Cyanobacterial toxins and toxin production. Phycologia 35: 12-24.

Sivonen K (2008) Emerging high throughput analyses of cyanobacteria toxins and toxic cyanobacteria. Adv Exp Med Biol 619: 539-557.

Sivonen K, Jones G (1999) Cyanobacterial toxins. In: Toxic Cyanobacteria in Water: A Guide to Their Public Health Consequences, Monitoring, and Management. Chorus I, Bartram J, eds, 41-111. E \& FN Spoon, London.

Stackebrandt E, Goebel BM (1994) Taxonomic note: a place for DNA/DNA reassociacion and 16S rRNA sequence analysis in the present species definition in bacteriology. Int J Syst Bacteriol 44: 846849

Starostwo Powiatowe w Kartuzach (2008) District Kartugy County Environmental Program for the years 2008-2011.

Stefaniak K, Kokocinski M (2005) Occurrence of invasive Cyanobacteria species in polimictic lakes of the Wielkopolska Region (Western Poland). Oceanological and Hydrobiological Studies 34: 137-148.

Stefaniak K, Kokocinski M, Messyasz B (2005) Dynamics of Planktothrix agardhii (Gom.) Anagn. et kom. blooms in polimictic Lake Laskownickie and Grylewskie (Wielkopolska Region) Poland. Oceanol Hydrobiol Studies 34: 125-136.

Taton A, Grubisic S, Brambilla E, De WR, Wilmotte A (2003) Cyanobacterial diversity in natural and artificial microbial mats of Lake Fryxell (McMurdo Dry Valleys, Antarctica): a morphological and molecular approach. Appl Environ Microbiol 69: 5157-5169.

Tillett D Dittmann E, Erhard M, von Döhren $H$, Börner $T$, Neilan BA (2000) Structural organization of microcystin biosynthesis in Microcystis aeruginosa PCC7806: An integrated peptide-polyketide synthetase system. Chem Biol 7: 753-764.

Toledo G, Palenik B (1997) Synechococcus diversity in the California current as seen by RNA polymerase $(r p o C 1)$ gene sequences of isolated strains. Appl Environ Microbiol 63: 4298-4303.

Vaitomaa J, Rantala A, Halinen K, Rouhiainen L, Tallberg P, Mokelke L, Sivonen K (2003) Quantitative Real-Time PCR for determination of microcystin synthetase E copy numbers for Microcystis and Anabaena in lakes. Appl Environ Microbiol 69: 7289-7297.

Valério E, Chambel L, Paulino S, Faria N, Pereira P, Tenreiro R (2009) Molecular identification, typing and traceability of cyanobacteria from freshwater reservoirs. Microbiology 155: 642-656.

Waleron M, Waleron K, Vincent WF, Wilmotte A (2007) Allochthonous inputs of riverine picocyanobacteria to coastal waters in the Arctic Ocean. FEMS Microbiol Ecol 59: 356-365.

WIOŚ Bydgoszcz - Regional Inspectorate for Environment Protection (2002) State of the Environment Report of the Kujawsko-Pomorskie Province in 2001.

WIOŚ Bydgoszcz (2006) State of the Environment Report of the KujawskoPomorskie Province in 2005.

WIOŚ Gdańsk (2002a) Assessment of the water purity of Lake Wysoka on the basis of studies carried out in 2001. Gdansk 2002. Communication.

WIOŚ Gdańsk. (2002b) State of the Environment Report of the Pomorskie Province in 2001.

WIOŚ Gdańsk (2003) State of the Environment Report of the Pomorskie Province by monitoring studies in 2002.

WIOŚ Gdańsk (2005) State of the Environment Report of the Pomorskie Province by monitoring studies in 2004.

WIOŚ Gdańsk (2006a) Assessment of the water purity of Lake Ostrayckie based on studies carried out in 2005.

WIOŚ Gdańsk (2006b) State of the Environment Report of the Pomorskie Province by monitoring studies in 2005. 
WIOŚ Gdańsk (2007) Assessment of the water purity of Lake Radunskie Dolne based on studies carried in 2006.

WIOŚ Gdańsk (2008) Assessment of the water purity of Lakes Suminskie, Schodno, Klasqtorne Duże, Wierzysko, Zajezierskie based on studies carried in 2007.

WIOŚ Gdańsk (2009) Assessment of the water purity of Lakes Maus\%, Wegorynno, Suminskie based on studies carried in 2008.

WIOS Gdańsk (2010) Monitoring of coastal and transitional waters carried in the frame of contract number) of $487 / 2009 / W n-11 / M N-P O / D$ on 8 th $\mathrm{Oc}$ tober 2009.

WIOŚ Olsztyn (2008) A study report on the Vistula Lagoon waters conducted by the Regional Inspectorate for Environmental Protection in Olsqtyn in years 2007-2008.

WIOŚ Poznań (2000). Conditions of the surface water - State of the environment reporting in Wielkopolska Province in 2000.
WIOŚ Poznań (2005) Assessment of the water purity of Lake Chodrieskie based on studies carried in 2005.

WIOŚ Poznań (2009) The ecological status of waters of Lake Bytyńskie based on test results from 2009. In: Summary of assessment of the ecological status of water bodies in 2009, in the Wielkopolska Region.

WIOS Szczecin (2011) State of the Environment Report of the Zachodniopomorskie Province in 2008-2009.

Witek Z, Jarosiewicz A (2010) The oxygen budget of two closed, dimictic lakes in the vicinity of Bytow (West Pomeranian Lake District, northern Poland). Int Jour Oceanography Hydrobiol 39: 135-145.

Yoshida M, Yoshida T, Satomi M, Takashima Y, Hosoda N, Hiroishi S (2008) Intra-specific phenotypic and genotypic variation in toxic cyanobacterial Microcystis strains. J Appl Microbiol 105: 407-15. 